\title{
Awareness and knowledge of Human Papillomavirus (HPV) infection among high-risk men of Hispanic origin attending a Sexually Transmitted Infection (STI) clinic
}

Vivian Colón-López ${ }^{1,2^{*}}$, Ana P Ortiz ${ }^{2,3}$, Lizbeth M Del Toro-Mejías ${ }^{3}$, Hermes García ${ }^{4}$, Michael C Clatts ${ }^{1}$ and Joel Palefsky ${ }^{5}$

\begin{abstract}
Background: Genital Human papilloma virus (HPV) is one of the most commonly diagnosed Sexually Transmitted Infection (STIS) in men and women. Knowledge about HPV infection among men is limited. This study aims to determine correlates of adequate knowledge of HPV infection among men who attend an STI clinic in Puerto Rico.

Methods: A cross-sectional study of 206 men was conducted at an STI clinic in San Juan, PR. Adequate knowledge was defined as a score of at least $70 \%$ of correct responses among those men who reported having ever heard of HPV. Variables that achieved statistical significance in the bivariate analysis $(p<0.05)$ were included in the multivariate logistic regression model.

Results: Although $52.5 \%$ of men reported having heard of HPV infection before the survey, only $29.3 \%$ of this sub-group had an adequate knowledge of HPV. Most men did not know that HPV is a risk factor for anal (38.7\%), penile (50.0\%) and oral (72.6\%) cancer. Factors associated with adequate knowledge of HPV in age-adjusted models were being men who have sex with men (MSM) $(\mathrm{OR}=2.6 ; 95 \% \mathrm{Cl}=1.1-6.1)$, self-report of genital warts (OR=3.2;95\% $\mathrm{Cl}=1.3-7.9)$ and herpes $(\mathrm{OR}=7.4 ; 95 \% \mathrm{Cl}=2.2-25.1)$. MSM was marginally associated with adequate knowledge $(\mathrm{OR}=2.3 ; 95 \% \mathrm{Cl}=0.9-5.9)$ and self-report of herpes remained significantly associated $(\mathrm{OR}=5.0 ; 95 \% \mathrm{Cl}=1.3-18.4)$ in multivariate logistic regression analysis.
\end{abstract}

Conclusions: Awareness and knowledge of HPV was very low in this group of men. Interventions to increase knowledge and awareness in this group are necessary to promote preventive practices for HPV-related cancers in high-risk groups.

Keywords: HPV, HPV knowledge, Men, Puerto Rico

\footnotetext{
* Correspondence: vivian.colon@upr.edu

${ }^{1}$ Department of Health Services Administration, Graduate School of Public Health, University of Puerto Rico, PO BOX 365067, San Juan 00936-5067, Puerto Rico

${ }^{2}$ Cancer Control and Population Sciences Program, Puerto Rico Comprehensive Cancer Center, University of Puerto Rico, 89 De Diego Ave. Suite 105m, San Juan 00927-6346, Puerto Rico

Full list of author information is available at the end of the article
} 


\section{Background}

Human papilloma virus (HPV) is one of the most commonly diagnosed STIs, with over 630 million HPV infections worldwide and an overall prevalence between 9-13\% [1]. A systematic review documented that the prevalence of HPV infection varies among men [2]. However, these wide estimates have been attributed to different sampling methods [2,3], as well as to differences in the populations studied [3]. Regarding HPV-related cancers, worldwide studies have reported presence of HPV infection for oropharyngeal [4], anal [5] and penile cancers [6]. Despite the reported global burden of HPV infection and HPV-related cancers in men [7], few studies have evaluated HPV and HPV-related cancer knowledge [8,9] particularly among high-risk men.

Although knowledge is not a direct predictor of health behavior [10], it is mediated by attitudes, risk perceptions, social influence and self-efficacy [11]. Thus, acquiring knowledge is a key first step to the success of any health education intervention. Although there has been increased attention to HPV awareness and knowledge in the literature $[12,13]$, most of the available research has focused on women $[11,14,15]$. Studies in men, particularly among those of Hispanic origin, are scarce. Among the few studies that have evaluated gender differences, men have lower knowledge about HPV compared to women [16,17].

In Puerto Rico (PR), despite the HIV epidemic and documented high-risk sexual practices in populationbased studies [18,19], there is limited epidemiological and behavioral research on knowledge of HPV infection, particularly among high-risk groups; this may delay the development of effective interventions to reduce the burden of HPV infection. This kind of research is necessary, given that epidemiological evidence indicates that men in PR, particularly $\mathrm{HIV}+$ men, have higher rates of HPV-related cancers compared to the general population of PR [20]. Therefore, in order to understand the determinants of knowledge of HPV infection, it is necessary to evaluate high-risk groups, particularly individuals whose average rate of acquisition of new sexual partners is sufficiently high to maintain increasing numbers of secondary infections. STI clinics can be an ideal setting for reaching these high-risk groups [21]. Studies in STI clinics have reported high prevalence estimates of HPV infection; but knowledge in patients from these settings is limited [22-24]. This study aims to describe the proportion of men that attend an STI clinic in PR who are aware of HPV, determine their level of knowledge about HPV infection, and identify correlates of HPV knowledge within this group.

\section{Methods}

This study was part of an ongoing epidemiological core study among men and women attending the Latin
American Center for Sexually Transmitted Diseases (CLETS, by its initials in Spanish), located in San Juan, Puerto Rico A full description of the methodology used in the core study has been described elsewhere [25]. Briefly, it involved recruitment of men and women from the clinic waiting, coupled with subsequent screening to confirm eligibility (at least 16 years of age) and capacity for informed consent. Study participation was voluntary and written informed consent was obtained. Study subjects participated in a structured behavioral interview that was administered by the research staff and data were recorded utilizing QDS software [26]. Domains in the survey included demographic characteristics (age, education, income, employment status, and marital status); number of female sexual partners (last 90 days), sexual identity (Men who have Sex with Men (MSM), non-MSM), consumption of alcohol, tobacco or illegal substances (last 90 days); sexual history and selfreported history of STIs; and current sexual risk profile (last 90 days).

Following completion of the core survey interview, all male participants were informed of the opportunity to participate in an additional interview as part of an HPV study. Men expressing interest in the HPV study were required to provide additional written informed consent for a second interview, which included questions regarding HPV awareness, HPV knowledge, perceived susceptibility to HPV-related cancers, HPV vaccine awareness, and willingness to be vaccinated against HPV.

Data collection procedures were approved by the University of Puerto Rico, Medical Sciences Campus Institutional Review Board (UPR-IRB).

\section{HPV knowledge}

Based on both existing measures [27] and additional input from the study team, a 21-item scale measure was used to address HPV knowledge. Response options included true, false and don't know. An incorrect or 'don't know' answer was given a score of 0. An example of items included in this scale was 'only women can get infected with $H P V$. Latter sets of questions were assessed only among those who reported having heard of HPV infection before the survey $(n=106)$, or $52.5 \%$ of the total sample.

\section{Statistical analysis}

Exploratory factor analysis of the 21 item scale measuring HPV knowledge identified 4 subscales, in which one factor (15 item scale) was related to HPV knowledge. Chrombach alpha for the 15 item scale was 0.75 .

A mean knowledge score was computed by summing correct responses of the 15 item scale, with higher scores meaning a higher knowledge. Adequate knowledge was defined as a minimum score of $70 \%$ [28]. Chi-square 
Table 1 Factors associated with adequate HPV knowledge among men aware of HPV, attending an STI clinic in Puerto Rico

\begin{tabular}{l} 
Variables \\
\hline Sociodemographic characteristics \\
Age (years)
\end{tabular}

Age (years)

Mean \pm SD

$37.8 \pm 13.1$

Educational Level

$<$ High School
High School
$>$ High School

Employment

No

Yes

Individual Annual Income

None

$<\$ 15,000$

$\geq \$ 15,000$

Health Insurance

None

Public

Private

Behavioral Factors

Tobacco Use (last 90 days)

$\begin{array}{lc}\text { No } & 96(47.5) \\ \text { Yes } & 106(52.5)\end{array}$

Alcohol Use (last 90 days)

No

Yes

Drug Use (last 90 days)

No

Yes

Female Sexual Partners (last 90 days)

None

1 partner

$>1$ partner

Sexual Identity

Non-MSM

MSM

Lifetime history of STls (self-reported)

Herpes

No

Yes

Gonorrhea

No

Yes
82 (40.6)

$120(59.4)$

128(63.4)

$74(36.6)$

$36(17.8)$

$74(36.6)$

$92(45.5)$

$77(38.1)$

$125(61.9)$

$57(28.2)$

$104(51.5)$

$41(20.3)$

$37(18.3)$

119 (58.9)

39 (19.3)

$100(49.5)$

77 (38.1)

25 (12.4)

0.028

$142(70.3)$

59 (29.2)

$171(84.7)$

$30(14.9)$

$170(84.2)$

$31(15.3)$
$36.6 \pm 13.2$

$41.3 \pm 17.4$

Adequate HPV Knowledge ${ }^{*}(n=106)$

No (\%) Yes (\%) $\quad$ p-value $^{* *}$

0.969

0.607

9 (12.0)

3 (9.7)

$9(29.0)$

19 (61.3)

38 (50.7)

0.915

21 (28.0)

9 (29.0)

$22(71.0)$

5 (16.1)

$20(64.5)$

6 (19.4)

4 (13.8)

8 (27.6)

17 (58.6)
32 (42.7)

$43(57.3)$

26 (34.7)

49 (65.3)

44 (58.7)

31 (41.3)

37 (49.3)

28 (37.3)

10 (13.3)

51 (68.0)

24 (32.0)

17 (54.8)

14 (45.2)

10 (32.3)

21 (67.7)

23 (74.2)

8 (25.8)

17 (54.8)

$12(38.7)$

$2(6.5)$

14 (45.2)

17 (54.8)

$0.001^{* *}$

70 (93.3)

21 (67.7)

10 (32.3)

0.120 


\begin{tabular}{|c|c|c|c|c|}
\hline HIV & & & & 0.913 \\
\hline No & $118(58.4)$ & $42(56.0)$ & $17(54.8)$ & \\
\hline Yes & 84 (41.6) & $33(44.0)$ & $14(45.2)$ & \\
\hline Genital Warts & & & & 0.009 \\
\hline No & 156 (77.3) & $58(77.3)$ & 16 (51.6) & \\
\hline Yes & $45(22.3)$ & $17(22.7)$ & $15(48.4)$ & \\
\hline Chlamydia & & & & $1.000^{* *}$ \\
\hline No & 179 (88.6) & $68(90.7)$ & $28(90.3)$ & \\
\hline Yes & $21(10.4)$ & $7(9.3)$ & $3(9.7)$ & \\
\hline Syphilis & & & & 0.530 \\
\hline No & $168(83.2)$ & $62(82.7)$ & $24(77.4)$ & \\
\hline Yes & $33(16.3)$ & $13(17.3)$ & 7 (22.6) & \\
\hline
\end{tabular}

"Only those that reported having heard about HPV were included in this analysis. Adequate knowledge was defined as a score of at least $70 \%$ of the correct responses.

${ }^{* *}$ Fisher's exact tests were performed.

tests were used to identify relationships between demographic and behavioral characteristics, and self-reported STIs with adequate HPV knowledge. Variables that achieved statistical significance $(\mathrm{p}<0.05)$ were assessed in the logistic regression models. Due to the reported association between age and HPV knowledge in the literature [29], Model 1 was adjusted for age. Then, a multivariate logistic regression model was performed (Model 2) to determine predictors of adequate HPV knowledge after controlling by all the independent variables in the model. All statistical analyses were performed using the statistical package SAS (Version 9.1,Cary,NC).

\section{Results}

\section{Participants' characteristics}

A total of 206 men participated in the study, of which 202 (98.1\%) completed the full assessment (behavioral interview and HPV supplement). Demographic and individual HPV risk-related characteristics are shown in Table 1 . The mean age of the study participants was 37.8 years $(\mathrm{SD}=13.12)$. Over half $(54.4 \%)$ had less than high school education; $61.9 \%$ were employed at the time of the interview. Nearly $20 \%$ were without medical insurance (neither private nor government-sponsored plan).

\section{Recent tobacco, alcohol and drug use}

More than half reported recent (last 90 days) use of tobacco $(52.5 \%)$ and alcohol (59.4\%). More than a third (36.6\%) reported recent illicit drug use.

\section{Sexual behaviors and practices}

$12.4 \%$ of the men interviewed have had more than one sexual partner in the last 3 months. A significant proportion of study participants identified as being men who have sex with men (MSM) (29.2\%). Among those reporting vaginal sex, more than a half $(56.9 \%)$ reported condom use in their last sexual intercourse, and 33.7\% of the participants were circumcised (data not shown).

\section{HPV knowledge}

More than half $(52.5 \% ; n=106)$ of the sample had heard about HPV infection before the survey. Primary sources of information included television (24\%), print media (e.g., magazines, newspapers, etc.) (13\%), and health care professionals $(10.5 \%)$ (data not shown). However, only $29.3 \%$ of these men demonstrated an adequate level of knowledge of HPV. Table 2 shows the absolute and relative frequencies of correct answers for each item scored regarding HPV knowledge. The proportion of the correct responses ranged from $16.0 \%$ to $90.6 \%$. Most knew that HPV is a sexually transmitted infection (85.9\%). However, more than half $58.5 \%$ were unaware that genital HPV is transmitted through skin-to-skin contact. With respect to knowledge of the long-term consequences of HPV infection, half (50.0\%) were aware that HPV can cause penile cancer and just $27.4 \%$ knew that HPV infection has a role in oral cancer. Conversely, $38.7 \%$ of men were unaware of the link between HPV and anal cancer.

Table 1 shows the association between demographic, behavioral and clinical factors associated with adequate knowledge of HPV. Factors significantly associated with adequate HPV knowledge in bivariate analyses were being MSM ( $p<0.028)$, having a self-reported history of herpes infection $(\mathrm{p}<0.001)$, and a self-reported history of genital warts $(\mathrm{p}<0.009)$.

Table 3 shows the results of the age-adjusted and multivariate logistic regression models evaluating factors associated with adequate HPV knowledge among men. 
Table 2 Absolute and relative frequencies of correct answers for each item scored regarding HPV knowledge $(n=106)$

\begin{tabular}{|c|c|c|}
\hline Item & Frequency & $\%$ Correct \\
\hline 1. Genital warts are caused by HPV & 70 & 66.04 \\
\hline 2. HPV is a virus that can cause cervical cancer & 82 & 77.36 \\
\hline $\begin{array}{l}\text { 3. I can infect my sexual partner with HPV, } \\
\text { even though I don't present the symptoms }\end{array}$ & 86 & 81.13 \\
\hline 4. HPV can cause genital warts in the penis & 60 & 56.60 \\
\hline 5. HPV can cause genital warts in the anus & 55 & 51.89 \\
\hline 6. HPV can cause penile cancer & 53 & 50.00 \\
\hline 7. HPV is sexually transmitted & 91 & 85.85 \\
\hline $\begin{array}{l}\text { 8. As more sexual partners I get, more the } \\
\text { risk of getting infected with HPV }\end{array}$ & 96 & 90.57 \\
\hline 9. There are many HPV types & 63 & 59.43 \\
\hline 10. HPV is associated with oral cancer & 29 & 27.36 \\
\hline $\begin{array}{l}\text { 11. Some HPV types can disappear } \\
\text { without treatment }\end{array}$ & 32 & 30.19 \\
\hline $\begin{array}{l}\text { 12. Genital HPV is transmitted through } \\
\text { skin by skin contact }\end{array}$ & 44 & 41.51 \\
\hline 13. Condom use prevents HPV infection ${ }^{*}$ & 63 & 59.43 \\
\hline 14. All HPV types cause cancer ${ }^{*}$ & 47 & 44.34 \\
\hline 15. HPV can cause anal cancer & 65 & 61.32 \\
\hline
\end{tabular}

Mean Score \pm SD: $8.8 \pm 3.5$ points.

${ }^{\sharp}$ Items 13 and 14 were false.

In the age-adjusted model, men who have identified as MSM were almost three times more likely to have an adequate knowledge of HPV compared to Non-MSM (age-adjusted $\mathrm{OR}=2.59 ; 95 \% \mathrm{CI}=1.10-6.11$ ). Men who reported a history of herpes (age-adjusted OR $=7.38$; $95 \%$ $\mathrm{CI}=2.17-25.06$ ) and genital warts (age-adjusted $\mathrm{OR}=3.22$; $95 \% \mathrm{CI}=1.32-7.85)$ also were more likely to have adequate knowledge of HPV. In multivariate models (Table 3), only having a history of herpes infection

Table 3 Logistic regression models of factors associated to adequate HPV knowledge

\begin{tabular}{|c|c|c|c|c|}
\hline \multirow[b]{2}{*}{ Variables } & \multicolumn{2}{|c|}{ Model $1^{\dagger}$} & \multicolumn{2}{|c|}{ Model $2^{\ddagger}$} \\
\hline & OR $(95 \% \mathrm{Cl})$ & P-value & OR $(95 \% \mathrm{CI})$ & P-value \\
\hline Sexual Identity & & 0.030 & & 0.070 \\
\hline Non-MSM & 1.00 & & 1.00 & \\
\hline MSM & $2.59(1.10-6.11)$ & & $2.34(0.93-5.88)$ & \\
\hline Herpes & & 0.001 & & 0.016 \\
\hline No & 1.00 & & 1.00 & \\
\hline Yes & $7.38(2.17-25.06)$ & & $4.97(1.34-18.41)$ & \\
\hline Genital warts & & 0.010 & & 0.121 \\
\hline No & 1.00 & & 1.00 & \\
\hline Yes & $3.22(1.32-7.85)$ & & $2.19(0.81-5.91)$ & \\
\hline
\end{tabular}

${ }^{\dagger}$ Model 1: Adjusted by age.

₹ Model 2: Adjusted by age, sexual identity, self-reported history of herpes and genital warts. remained positively associated with adequate HPV knowledge. MSM were up to two times more likely to have an adequate knowledge of HPV compared to nonMSM. However, this association achieved only marginal significance $(\mathrm{p}<0.07)$.

\section{Discussion}

To our knowledge, this is the first study to attempt to examine awareness of HPV infection among men in PR. In a sample in which none of the study participants has being vaccinated and the awareness of the vaccine is low [30], results show that despite acknowledgement by more than half of the sample that they had heard about HPV infection, a low proportion of study participants had adequate knowledge of HPV. It should be pointed out that among those men that were aware of HPV infection, high levels of knowledge regarding the association of HPV infection with cervical cancer and some risk factors (such as number of sexual partners) was reported. It is likely that the higher levels of adequate HPV knowledge among men with a self-reported history of STIs stems from education they received during the course of STI treatment. This suggests that STI service providers are a good source of education and also that HPV knowledge may be retained in this high-risk population, although further research in this area is warranted. Our results indicate that greater attention is needed to educate men about the potential long-term consequences of HPV infection, including increased risk for oral, penile, and anal cancers [31].

Common sources of HPV information that were identified in this study were television, magazine and newspaper, followed by health care professionals and physicians. These sources of information are inconsistent with results from the population-based 2009 HINTS survey in PR, which showed that the Internet is the primary source for cancer information used by the general population of PR [32]. A possible explanation for this discrepancy is that our study sample was recruited in an STI clinic and primarily comes from a low socioeconomic background. Thus, sources of information and health literacy in this group might differ to those from the general population. This needs to be further investigated in order to identify a mechanism for dissemination which will help to increase knowledge about HPV in this high-risk population.

After age-adjusted logistic regression analysis, a marginal association between MSM and adequate knowledge of HPV was observed. Findings from an online survey in the US show similar results [31]. In this study, $22 \%$ of MSM reported genital warts; therefore, knowledge of HPV infection might have been the result of their previous infection. Additionally, qualitative studies among MSM in Puerto Rico attending STI clinics have shown 
that knowledge of HPV-related cancers in this group is limited [33]. Since studies have demonstrated a high prevalence of HPV infection in MSM, along with a high rate of HPV-related anal cancer [34], this group constitutes a unique population that will greatly benefit from the development of health interventions to increase knowledge of HPV and of related morbidities.

Although results from this clinic-based study are of great relevance for the development of cancer prevention and control efforts among men in PR, our findings need to be interpreted with caution. Research in an STI setting has limitations. Primary among these is that our findings might not generalize to the general population. Specificity and complexity of some of the items of our HPV knowledge score also needs to be further explored for future efforts. Despite its potential limitations, data collected from a highly selective population, such as a public STI clinic, may also offer an opportunity to reach targeted high-risk groups more efficiently.

\section{Conclusion}

In summary, this study highlights the low prevalence of HPV awareness and of adequate knowledge of HPV infection in a sexually active group of men attending an STI clinic in Puerto Rico. Findings highlight the need to increase HPV awareness, primarily of HPV-related cancers such as oral and anal cancer. STI clinics might serve as venues for cancer prevention and control among high-risk men. In order to effectively moving forward strategies in these settings, further research which will help us understanding levels of health literacy, stratified by groups of interest, needs to be performed.

\section{Competing interests}

The authors declare that they have no competing interests.

\begin{abstract}
Authors' contributions
VCL worked on the conceptualization of the study, study design, data analysis and interpretation and manuscript preparation; APO worked on the study design, data interpretation and manuscript preparation; LMDT worked on data analysis, interpretation and manuscript preparation; JP worked on conceptualization of the study, manuscript preparation and interpretation of data; MCC worked on the study design; HG worked on conceptualization of the study, study design and interpretation. All authors read and approved the final manuscript.
\end{abstract}

\begin{abstract}
Acknowledgments
The project described above was fully supported by NIH R03 DA027939-01 and AIDS-Science Track Award for Research Transition A-START 1R03DA031590-01 from NIDA. We wish to express our gratitude to the undergraduate students from the University of Puerto Rico, Rio Piedras Campus and the graduate students from the University of Puerto Rico, Medical Sciences Campus, School of Public Health who participated as part of their research experience as well as the study participants, clinical staff faculty and other support personnel in CLETS for their help and support. Finally, we will like to thank Dr. Angela Pattatucci, for her reviews and suggestions pertaining this manuscript.
\end{abstract}

\section{Author details}

'Department of Health Services Administration, Graduate School of Public Health, University of Puerto Rico, PO BOX 365067, San Juan 00936-5067,
Puerto Rico. ${ }^{2}$ Cancer Control and Population Sciences Program, Puerto Rico Comprehensive Cancer Center, University of Puerto Rico, 89 De Diego Ave. Suite 105m, San Juan 00927-6346, Puerto Rico. ${ }^{3}$ Department of Biostatistics and Epidemiology, Graduate School of Public Health, University of Puerto Rico, PO BOX 365067, San Juan 00936-5067, Puerto Rico. ${ }^{4}$ Latin American Center for Sexually Transmitted Diseases, Puerto Rico Department of Health, San Juan 00927, Puerto Rico. ${ }^{5}$ Department of Medicine, UCSF, San Francisco, CA 94143-0126, San Francisco.

Received: 11 April 2012 Accepted: 7 December 2012

Published: 12 December 2012

\section{References}

1. Pagliusi S: Vaccines against Human Papillomavirus: World Health Organization; http://www.who.int/vaccines/en/hpvrd.shtml (accessed 29 March 2010).

2. Dunne EF, Nielson CM, Stone KM, Markowitz LE, Giuliano AR: Prevalence of HPV infection among men: a systematic review of the literature. I Infect Dis 2006, 194:1044-1057.

3. Nielson CM, Harris RB, Dunne EF, Abrahamsen M, Papenfuss MR, Flores R, Markowitz LE, Giuliano AR: Risk factors for anogenital human papillomavirus infection in men. J Infect Dis 2007, 196:1137-1145.

4. Kreimer AR, Clifford GM, Boyle P, Franceschi S: Human papillomavirus types in head and neck squamous cell carcinomas worldwide: a systematic review. Cancer Epidemiol Biomarkers Prev 2005, 14:467-475

5. De Vuyst H, Clifford GM, Nascimento MC, Madeleine MM, Franceschi S: Prevalence and type distribution of human papillomavirus in carcinoma and intraepithelial neoplasia of the vulva, vagina and anus: a metaanalysis. Int J Cancer 2009, 124:1626-1636.

6. Heideman DA, Waterboer T, Pawlita M, Delis-van Diemen P, Nindl I, Leijte JA, Bonfrer JM, Horenblas S, Meijer CJ, Snijders PJ: Human papillomavirus- 16 is the predominant type etiologically involved in penile squamous cell carcinoma. J Clin Oncol 2007, 25:4550-4556.

7. Giuliano AR, Tortolero-Luna G, Ferrer E, Burchell AN, de Sanjose S, Kjaer SK, Muñoz N, Schiffman M, Bosch FX: Epidemiology of human papillomavirus infection in men, cancers other than cervical and benign conditions. Vaccine 2008, 26(10):K17-K28.

8. Reiter PL, Brewer NT, Smith JS: Human papillomavirus knowledge and vaccine acceptability among a national sample of heterosexual men. Sex Transm Infect 2010, 86(3):241-246.

9. Baer $H$, Allen $S$, Braun $L$ : Knowledge of human papillomavirus infection among young adult men and women: implications for health education and research. $J$ Community Health 2000, 25(1):67-78.

10. Viswanath K, Breen N, Meissner H, Moser RP, Hesse B, Steele WR, Rakowski W: Cancer knowledge and disparities in the information age. J Health Commun 2006, 11(1):1-17.

11. Tiro JA, Meissner HI, Kobrin S, Chollette: What do women in the U.S. know about human papillomavirus and cervical cancer? Cancer Epidemiol Biomarkers Prev 2007, 16(2):288-294

12. Markham CM, Escobar-Chaves SL, Addy RC, Lewis H, Tortolero-Luna G, Tortolero SR: Knowledge and risk perception regarding HPV among Latino alternative school students in Houston, Texas. Tipica 2009, 5(1):32-38.

13. Liddon N, Hood J, Wynn BA, Markowitz LE: Acceptability of human papillomavirus vaccine for males: a review of the literature. J Adolesc Health 2010, 46(2):113-123.

14. Colón-López V, Ortiz AP, Palefsky J: Burden of human papillomavirus infection and related comorbidities in men: implications for research, disease prevention and health promotion among Hispanic men. P R Health Sci J 2010, 29(3):232-240.

15. Klug SJ, Hukelmann M, Blettner M: Knowledge about infection with human papillomavirus: a systematic review. Prev Med 2008, 46(2):87-98.

16. Nandwani MC: Men's knowledge of the human papillomavirus vaccine. Nurse Pract 2010, 35(11):32-39.

17. Baer $\mathrm{H}$, Allen $\mathrm{S}$, Braun $\mathrm{L}$ : Knowledge of human papillomavirus infection among young adult men and women: Implications for health education and research. J Commun Health 2000, 25:67-78.

18. Ortiz AP, Soto-Salgado M, Suárez E, del Carmen Santos-Ortiz M, Tortolero-Luna G, Pérez CM: Sexual behaviors among adults in Puerto Rico: a population-based study. J Sex Med 2011, 8(9):2439-2449. 
19. Colón-López V, Rodríguez-Díaz CE, Ortiz AP, Soto-Salgado M, Suárez E, Pérez CM: HIV-related risk behaviors among a sample of men who have sex with men in Puerto Rico: an overview of substance use and sexual practices. P R Health Sci J 2011, 30(2):65-68.

20. Ortiz AP, Pérez J, Soto-Salgado M, Palefsky J, Perez J, Colón-López V: Burden of Human Papilloma Virus (HPV) related cancers among persons living with AIDS in Puerto Rico:: Submitted to MMWR; 2012.

21. Darbes L, Crepaz N, Lyles C, Kennedy G, Rutherford G: The efficacy of behavioral interventions in reducing HIV risk behaviors and incident sexually transmitted diseases in heterosexual African Americans. AIDS 2008, 22(10):1177-1194.

22. Souza LM, Miller WM, Nery JA, Andrade AF, Asensi MD: A syphilis co-infection study in human papilloma virus patients attended in the sexually transmitted infection ambulatory clinic, Santa Casa de Misericordia Hospital, Rio de Janeiro, Brazil. Braz J Infect Dis 2009, 13(3):207-209.

23. Dempsey AF, Koutsky LA, Golden M: Potential impact of human papillomavirus vaccines on public STD clinic workloads and on opportunities to diagnose and treat other sexually transmitted diseases. Sex Transm Dis 2007, 34(7):503-507.

24. Svare El, Kjaer SK, Worm AM, Osterlind A, Meijer CJ, van den Brule AJ: Risk factors for genital HPV DNA in men resemble those found in women: a study of male attendees at a Danish STD clinic. Sex Transm Infect 2002, 78(3):215-218

25. Clatts MC, Rodríguez-Díaz CE, García H, Vargas-Molina RL, Colón-López V, Pérez-Rios N, Goldsamt L, Jovet-Toledo GG: Sexually transmitted infections clinics as strategic venues for targeting high-risk populations for HIV research and sexual health interventions. P R Health Sci J 2011. 30(3):101-108.

26. Questionnaire Development System: http://www.novaresearch.com/ Products/qds/index.cfm.

27. Ramirez JE, Ramos DM, Clayton L, Kanowitz S, Moscicki AB: Genital human papillomavirus infections: knowledge, perception of risk, and actual risk in a nonclinic population of young women. J Womens Health 1997, 6:113-121.

28. Soto-Salgado M, Suárez E, Ortiz AP, Adrovet S, Marrero E, Meléndez M, Colón HM, Albizu C, Del C, Santos M, Torres E, Pérez CM: Knowledge of viral hepatitis among Puerto Rican adults: implications for prevention. J Community Health 2011, 36(4):565-573.

29. Pelullo CP, Di Giuseppe G, Angelillo IF: Human papillomavirus infection: knowledge, attitudes, and behaviors among Lesbian, gay men, and bisexual in Italy. PLoS One 2012, 7(8):e42856.

30. Colón-López V, Del Toro-Mejías L, Ortiz AP, Tortolero-Luna G, Palefsky JM Awareness and willingness of the HPV vaccine among high-risk men attending an STI clinic in Puerto Rico. P R Health Sci J 2012, 4:227-231.

31. Brewer NT, Ng TW, McRee AL, Reiter PL: Men's beliefs about HPV-related disease. J Behav Med 2010, 33(4):274-281.

32. Tortolero-Luna G, Finney-Rutten LJ, Hesse BW, Davis T, Kornfeld J, Sanchez M, Moser RP, Ortiz AP, Serrano-Rodriguez RA, Davis K: Health and cancer information seeking practices and preferences in Puerto Rico: creating an evidence base for cancer communication efforts. $\int$ Health Commun 2010, 15(3):30-45.

33. Colón-López V, Ortiz AP, Pérez N, Pattatucci A: Understanding of HPV-related cancers among HIV+ individuals in Puerto Rico. Poster presented at The $27^{\text {th }}$ International Papillomavirus Conference. Berlin, Germany: 2011.

34. Palefsky JM: Human papillomavirus-related disease in men: not just a women's issue. J Adolesc Health 2010, 46(4):S12-S19.

Cite this article as: Colón-López et al:: Awareness and knowledge of Human Papillomavirus (HPV) infection among high-risk men of Hispanic origin attending a Sexually Transmitted Infection (STI) clinic. BMC Infectious Diseases 2012 12:346.

\section{Submit your next manuscript to BioMed Central and take full advantage of:}

- Convenient online submission

- Thorough peer review

- No space constraints or color figure charges

- Immediate publication on acceptance

- Inclusion in PubMed, CAS, Scopus and Google Scholar

- Research which is freely available for redistribution

Submit your manuscript at www.biomedcentral.com/submit
Ciomed Central 